\title{
How facial clefts are managed until the secondary early alveoplasty at the TREFLE* clinic
}

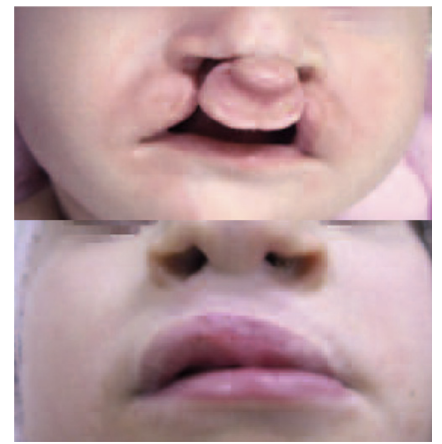

\section{Julien GODENĖCHE, Isabelle JAMES, Thiébaut KRAFT}

\begin{abstract}
For many years TREFLE, The Ecully team treating labio-palatal clefts, has begun managing the care of patients with clefts at younger and younger ages. Both surgically and orthodontically we design our therapeutic interventions to change the environment of the cleft as rapidly as possible in order to improve patients' functioning that will in turn have a beneficial effect on growth and esthetics. We have found that our patients treated in this way not only have improved appearance but also less likelihood of needing orthognathic surgery. We have also found that our patients do not routinely require early bone grafts, at about 6 years of age. We determine which children will require this intervention in a re-evaluation that we undertake after the completion of the primary phase of orthopedic and orthodontic therapy.

To make our technique as clear as possible throughout the course of this article we present the different stages of treatment of four children, Leslie, Jules, Nathan, and Élodie.
\end{abstract}

\section{KEY WORDS}

Labio-alveolar-palatal clefts,

Bone graft,

Early secondary alveoloplasty,

Multi-disciplinary rehabilitation.

*Ecully team treating labio-palatal clefts 


\section{1 - INTRODUCTION}

Multi-disciplinary management of the treatment of cleft palate patients is beneficial not only for patients and their families but also for practitioners of the various specialties teaching them to make judgments on the basis of data that they are not always previously familiar with. This considerable mutual enrichment creates a climate of confidence that ameliorates the global management of therapy. In being forced to confront the therapeutic imperatives of all their colleagues participants have been able to improve the timing and the techniques of treatment. Families of patients always

\section{2 - THE FIRST SURGICAL PROCEDURE}

The different treatment techniques and scheduling programs that the many French and international cleft palate treatment teams adhere to are usually related to the type of training the plastic, pediatric, and maxillo-facial surgical participants have had.

For 17 years we have operated on our patients' soft palates when they reached the age of 3 months and repaired the lip, palatal, and gingival clefts at 6 months, also performing a gingivoplasty if possible, in accordance with the schedule of René Malek $^{12}$. The effectiveness of an early veloplasty in a cleft palate patient's acquisition of speaking skills has been well demonstrated.

Stimulated by the work of the French teams of J.-C Talmant ${ }^{17}$ in Nantes and M. P. Vazquez ${ }^{2}$ in Paris (Trousseau), since 2010 we have been operating on the soft palates, the lips, participate in staff discussions designed to improve the well-being and comfort of patients. This inclusion of parents as auxiliary members of the treatment team is one of the points cited by the study of Prahl Andersen ${ }^{15}$ that observed, "Do not add unnecessary procedures to the treatment because the major goal of the treatment team is to insure that cleft palate patients live through infancy and adolescence in a way that is as close as possible to the lives their comrades enjoy." We believe that is a worthy challenge.

and the noses of 3 month-old patients and on their hard palates when they reached the age of 6 months. In closing the hard palate we rely on decollement, or separation of tissues without mobilizing the fibro-mucosa or making any lateral incisions that would leave areas of scarring that could later interfere with anterior and transverse growth (fig. 1a to d).

Our goal of always focusing our surgery on functional goals has impelled us to make these technical modifications. Basing our efforts on increasingly early adjustment of anatomic structures that play important functional roles seems to us the best way to guarantee harmonious growth for our patients.

Using the soft palate repair procedure that Sommerlad ${ }^{16}$ described we have been able to improve performance of the soft palate considerably, 


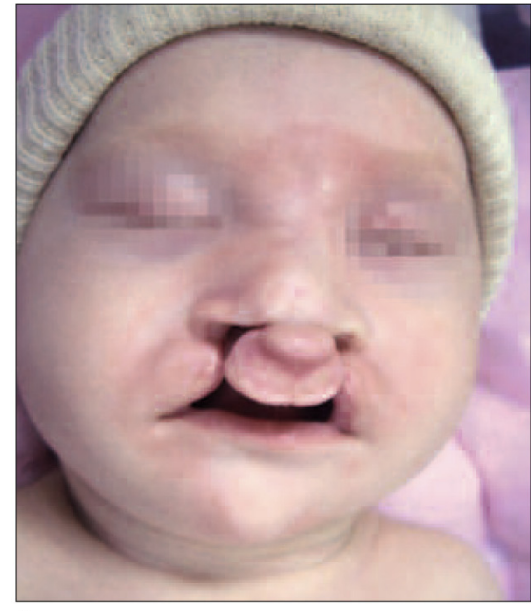

a

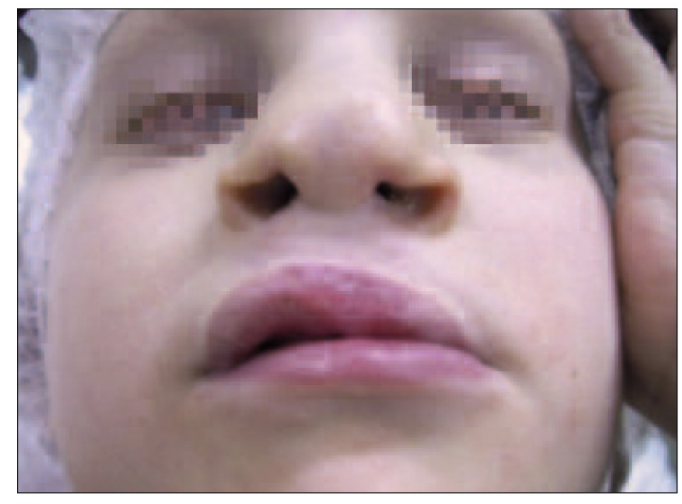

C

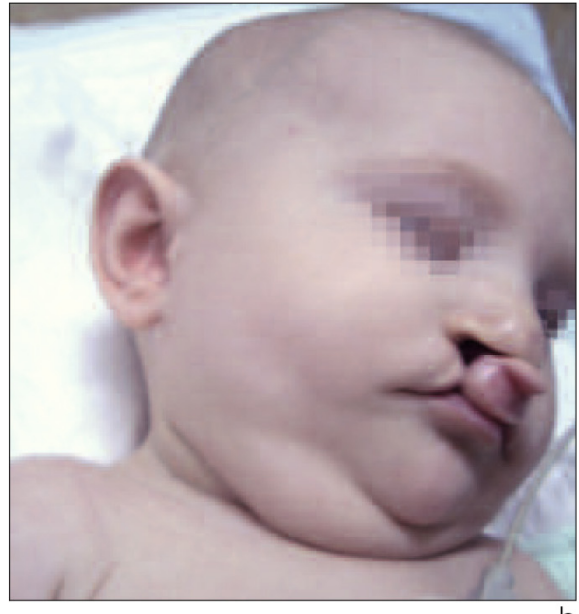

b

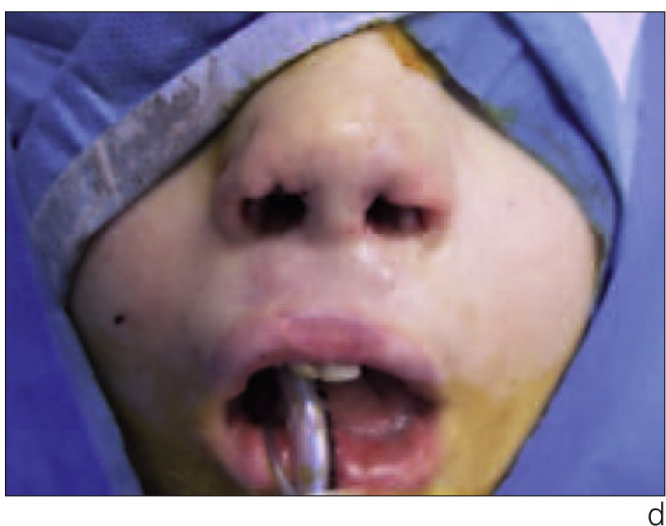

Figures 1 a to $d$

Élodie: development until nose repair after bone graft.

achieving for patients with all types of clefts an $85 \%$ rate of class 1 phonation even before they have begun speech-language therapy (fig. 2 a to d).

Repair of the lip by reconstruction of the muscle band and rejoining the external borders of the cleft at the level of the anterior nasal spine stimulates a rotation of the larger fragment. We use Malek's plastic surgery procedure ${ }^{12}$ in the form of a double $Z$ to maintain a little excess of skin of the cleft borders to construct a philtrum crest with the smallest possible triangular flaps, never passing the midline and blending the peak of the triangle with the base of the nose (fig. 3). The dissection being periosteal, we suture the homologous planes (fig. $4 a$ and $b$, and fig. $5 a$ and $b$ ).

After the initial procedure, obtaining good nasal respiration for our patients is an indispensable aspect of the repair. It not only allows patients to enjoy better growth of the middle part of the face but also prevents their tongues from assuming a low posture that could cause mandibular protru$\operatorname{sion}^{13}$. That is why we replace the mesial crus of the alar cartilage in the 


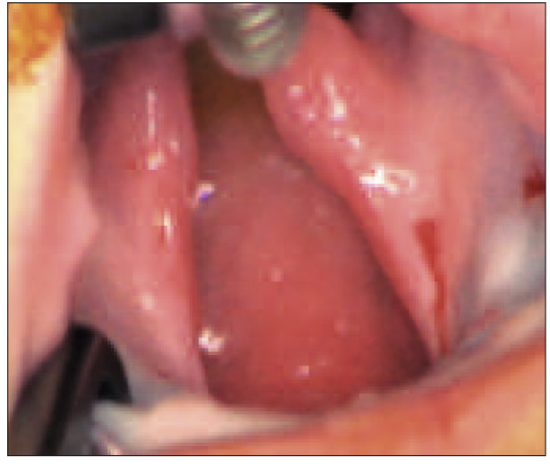

a

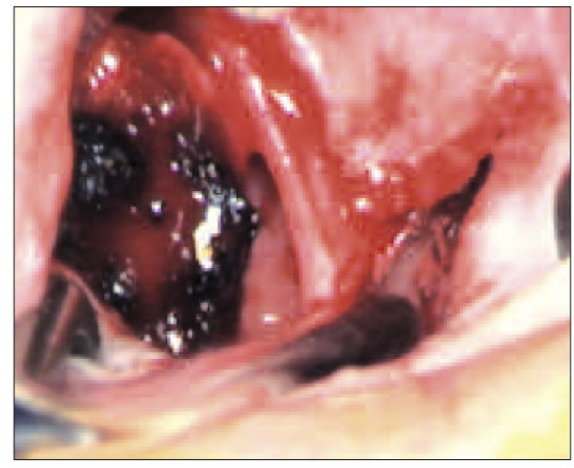

b

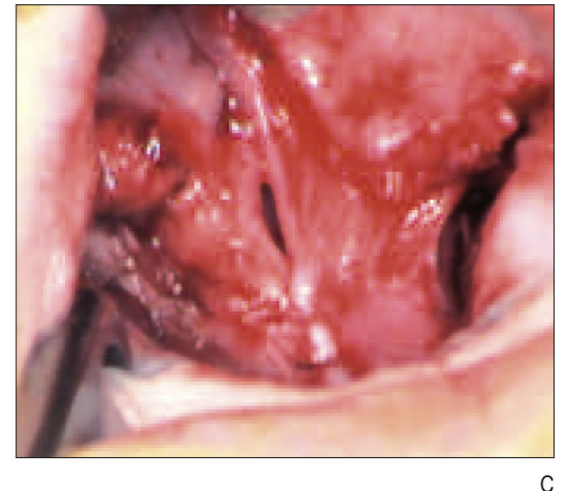

Figures 2 a to $d$ Soft palate surgery.

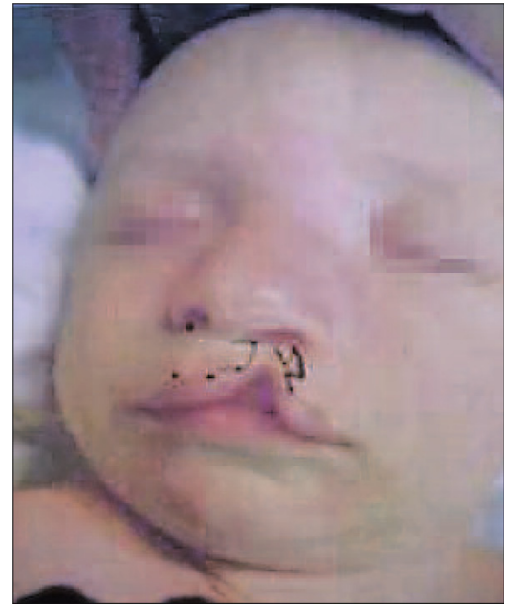

Figure 3

Malek's plastic surgery.

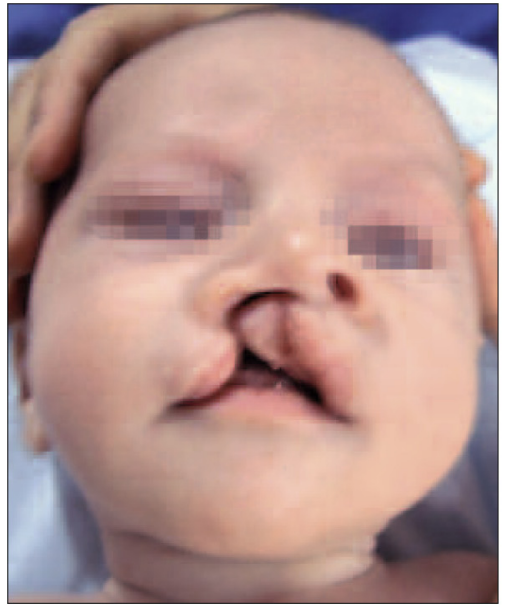

a

first surgical procedure and postpone placement of a nasal splint until the patient's second month of life.

In our view, the only defect that should not be treated in the initial

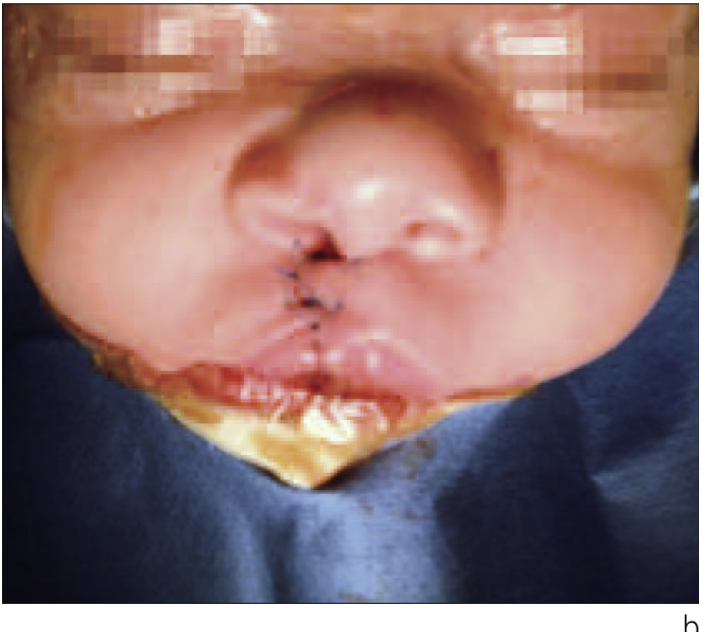

Figures $4 a$ and $b$ Jules. procedure is the distal position of the small fragment in the most asymmetric clefts on the antero-postero surface. This is the source of a lack of force on the external lip and poor 


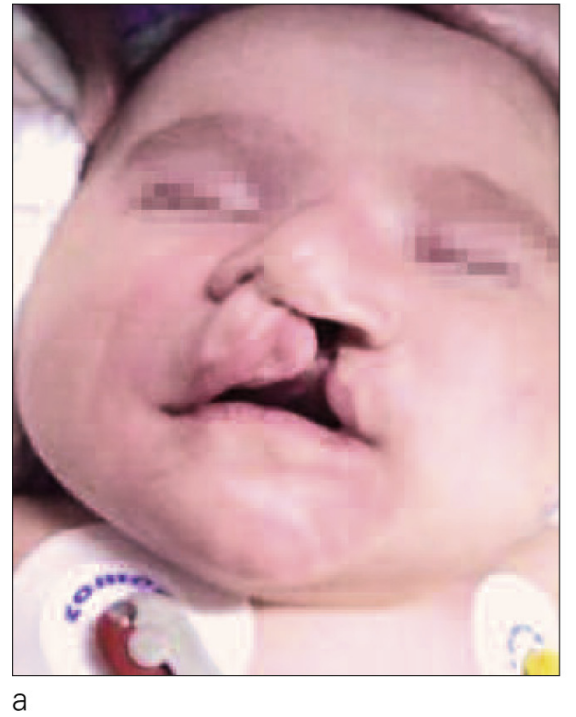

a

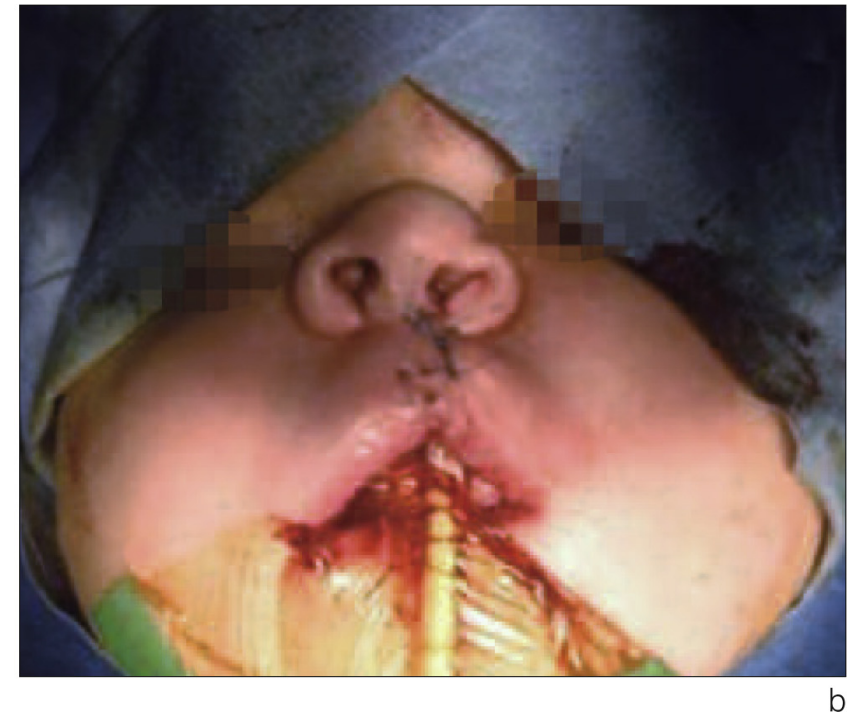

Figures $5 a$ and $b$ Leslie. support for the nasal wing. Early orthodontic treatment with a quad helix or a rapid palate expander can substantially improve this discrepancy. On our team orthodontists begin this therapy on 4 or 5 year-olds while Talmant and Lumineau commence on 3 year-olds. Surgeons can perform a septoplasty at the same time they place a maxillary bone graft, which supports the lip and raises the base of the nose, greatly improving the appearance of the patient's midface $^{11}$ (fig. 6 a to g). We perform this operation early because its esthetic benefits greatly ease the socialization process that entering primary school entails.

We noted during the 2010 meeting of the French Association of Facial Clefts in Marseille a consensus of the national treatment teams for a lowering of the age of patients receiving grafts, if possible at 6 years of age and, in all cases, certainly before eruption of upper canine teeth.

In an examination of the gaps between edges of clefts of 4 year olds, many types can be discerned:

- the upper right or left lateral incisors are present and supported by substantial basal bone, which is the most favorable situation;

- the upper right or left lateral incisors are present but not supported by adequate amounts of bone. There will be a risk of these teeth being lost as they erupt or if orthodontists attempt to mobilize them for treatment when they are ectopic or rotated, which are frequent occurrences;

- one or both upper lateral Incisors are absent, making it necessary for oral surgeons to place a bone graft in the affected region or regions to 


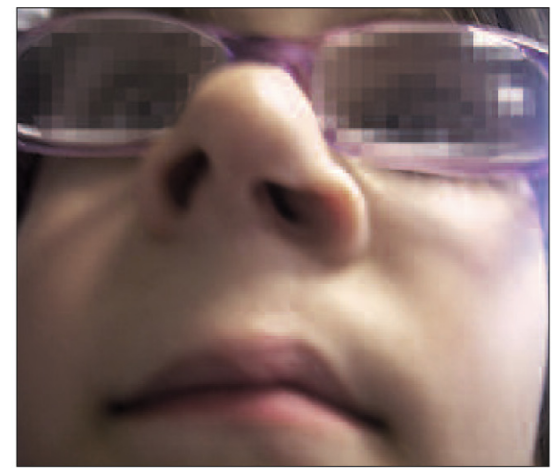

a
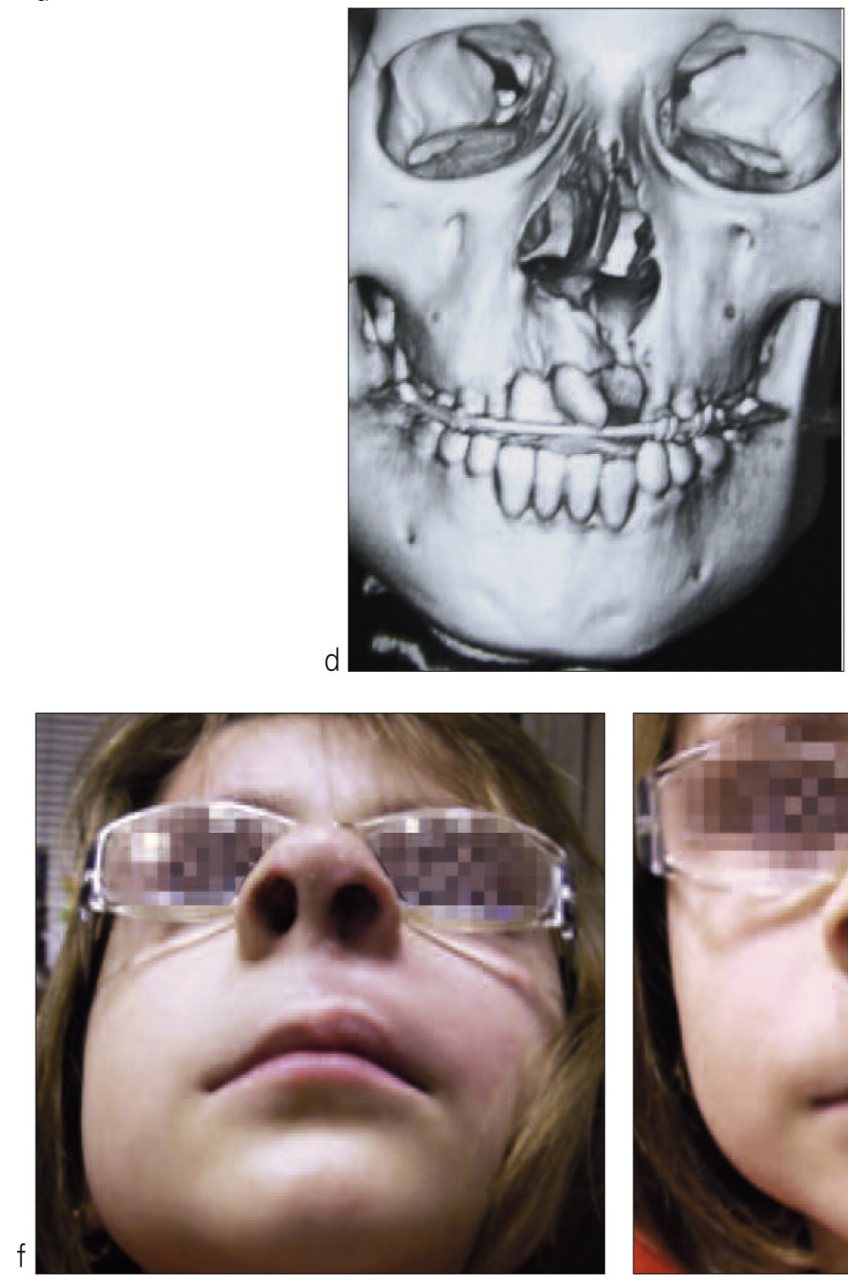

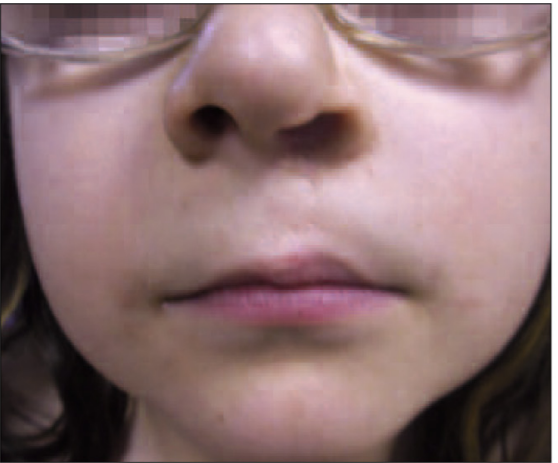

b

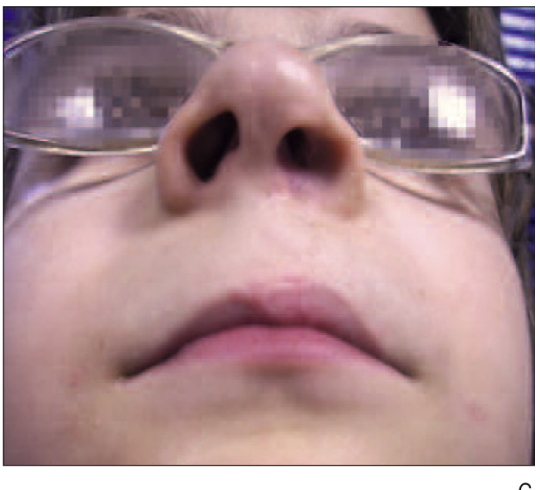

c

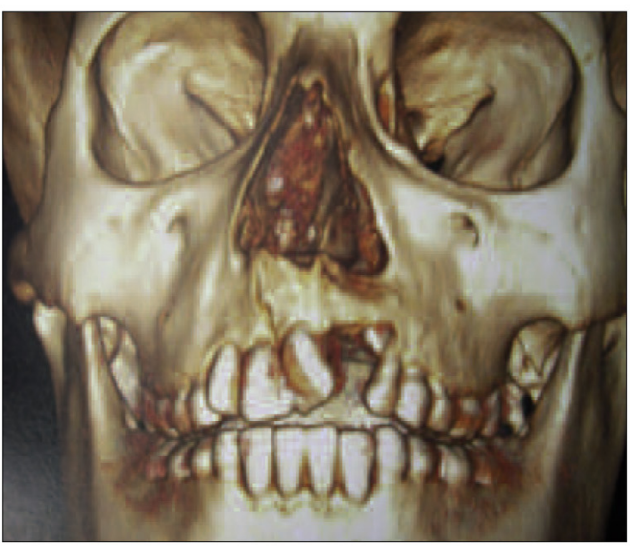

e

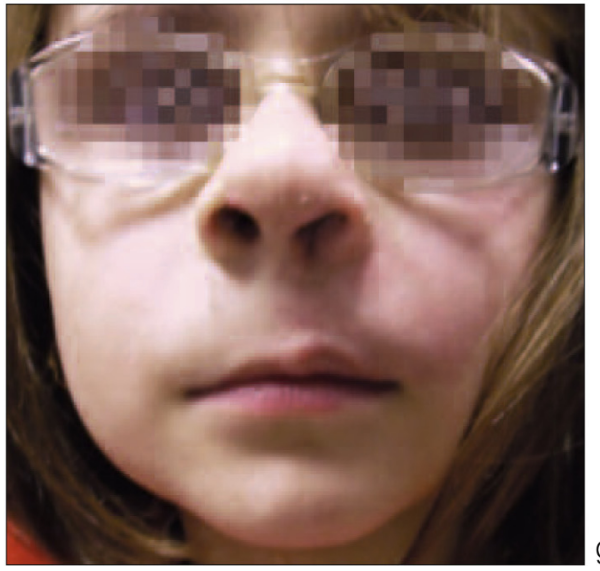

Figures 6 a to $g$ Leslie.

a: at the age of 4;

$b, c$ : after the first orthodontic; stage, one can see the base; of the nostrils rising;

$d$ : pre-operative scanning view;

e: post-operative scanning view;

$f, g$ : after early placement of a graft in association with

an anterior rhinoplasty. 
stabilize the fragments and to support an eventual implant (it now being universally agreed that closing spaces left by congenitally absent upper laterals not only impairs growth but also leads to an unsightly midline discrepancies).

So it is evident that cleft palate patients usually need maxillary bone grafts both for functional and esthetic reasons. For successful outcomes, collaboration on the scheduling of procedures between members of the multi-disciplinary team is essential. Team members should re-evaluate cleft palate patients once a year and in the consultation for 4 year olds they should take full radiographic records consisting of a panoramic film and a profile cephalogram with teeth in occlusion and then elaborate their treatment plans. For many patients a scanner film with a 3 dimensional reconstruction may be needed for an adequate assessment of osseous requirements.

\section{3 - EARLY ORTHOPEDIC AND ORTHODONTIC TREATMENT}

As we have noted, orthopedic treatment does not begin until after the multi-disciplinary consultation has been completed and the need for a bone graft evaluated, an assessment that is renewed regularly after initial treatment. In certain cases, a 6 month recall is set up if an early graft had not been deemed necessary or if the cost benefits analysis had not authorized a go-ahead at that stage of the patient's dentition. In some types of clefts, at the mixed dentition stage the eruption of permanent teeth modifies the osseous environment enough to make postponement of the graft advisable.

Nevertheless, in most cases an early secondary alveoplasty bestows considerable amelioration of the cleft environment in terms of the teeth, the alveolar processes, and basal bone as well as in over-all functional and esthetic aspects.

Our orthodontic objectives are to:

- stabilize the separated osseous fragments;
- correct malpositioned incisor teeth and establish a favorable milieu for their assuming a correct position in the dental arch;

- achieve normal maxillary arch form;

- correct all cross bites.

The appliances we most frequently employ are the quad helix and the rapid palatal expander, a device that, even when no true maxillary retrusion is present, has the capability of promoting development of the pre-maxilla as well as improving nasal respiration. In addition, it ameliorates support of the lips and the nostrils. And, finally, re-arrangement of the incisal zone after rapid palatal expansion means that this area will be well on the road to proper development in the mixed dentition stage.

By adding a full banded and bonded appliance to rapid palatal expansion therapy, orthodontists can considerably improve arch preparation for placement of the graft. With it, 

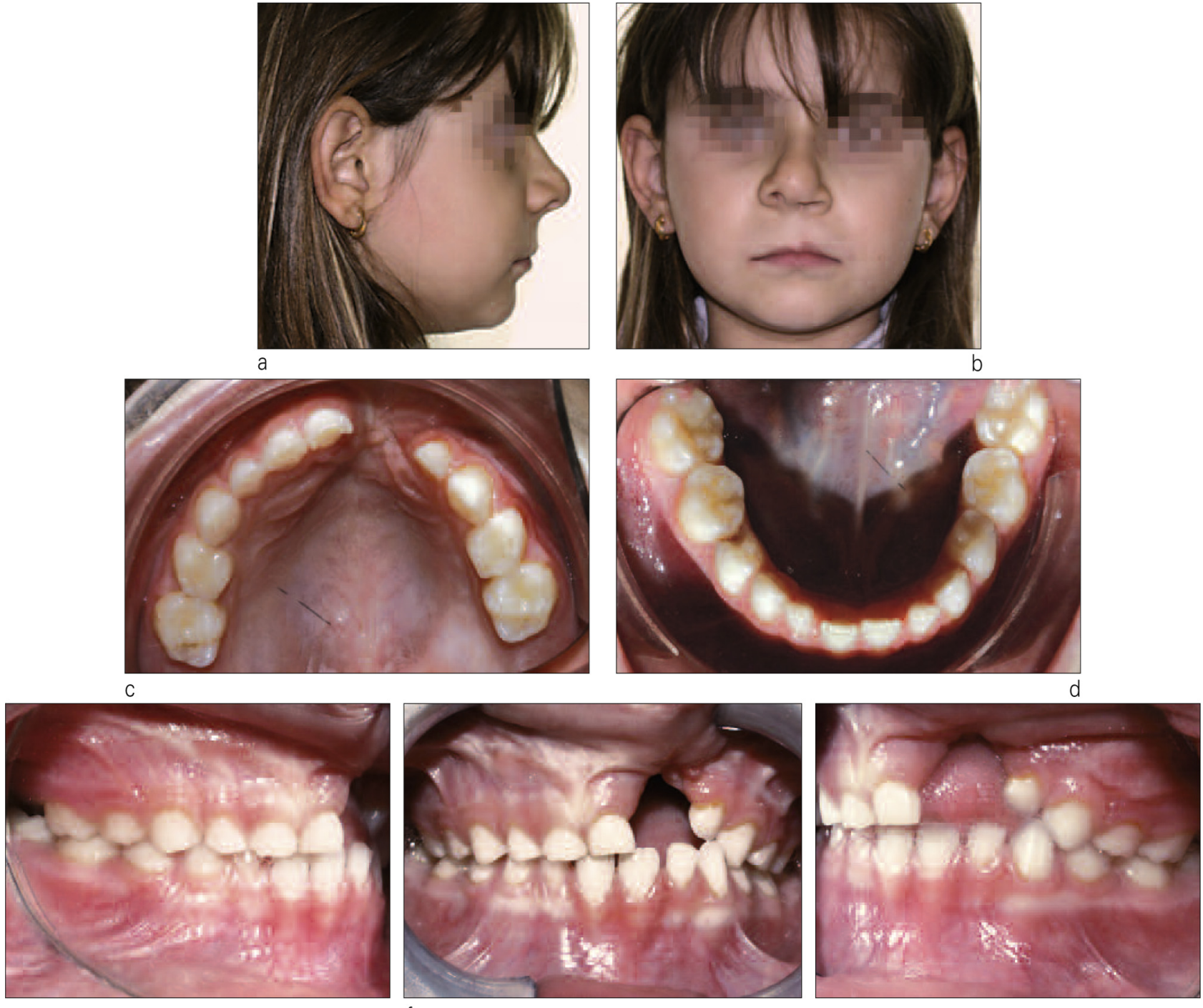

e

f

Figures 7 a to $\mathrm{g}$

Case 1. Leslie: before orthodontic treatment.

orthodontists can facilitate correction of arch form and reduce the extent of large cleft gaps (case $\mathbf{n}^{\mathbf{0}} \mathbf{1}$ : Leslie (fig. $7 \mathrm{a}$ to $\mathrm{g}$ and fig. 8 a to c) and, above all, precisely position teeth near the cleft. This will promote better quality of the surgical intervention in terms of optimal bone growth and improved gingival management.
Case $\mathbf{n}^{\mathbf{0}}$ 2: Jules (fig. 9 a to f).

Case $\mathbf{n}^{\mathbf{0}}$ 3: Nathan (fig. 10 a to I, fig. 11 a to $f$, and fig. 12 a to $\mathrm{c}$ and fig. 13)

Case $\mathbf{n}^{\circ}$ 4: Élodie (fig. 14 a to I, fig. 15 and fig. 16 a to g).

After orthodontic preparation is completed, orthodontists can adjust 

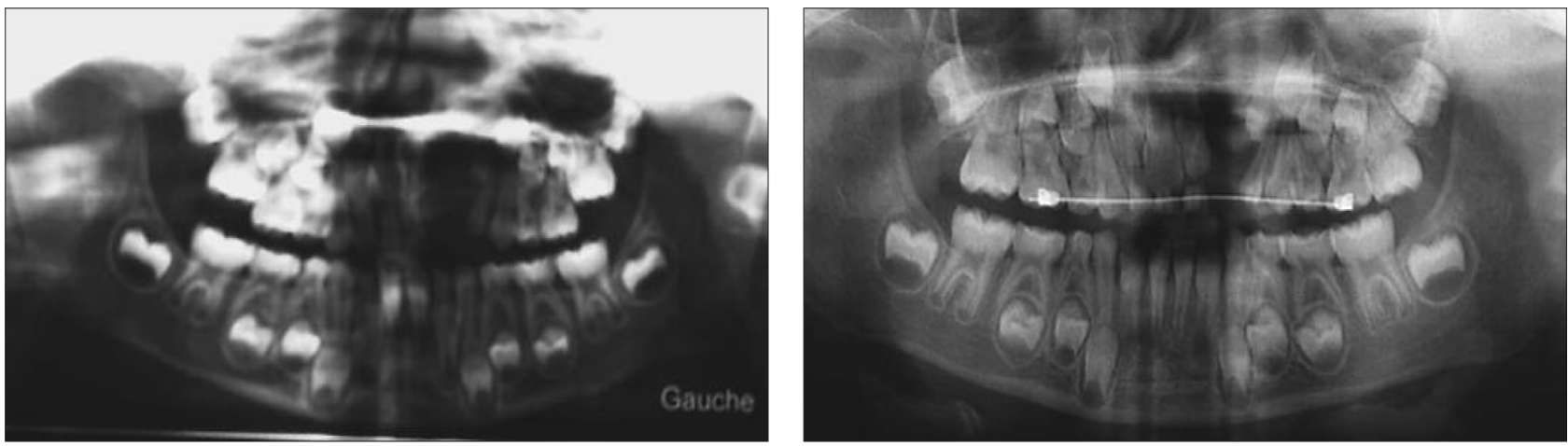

a

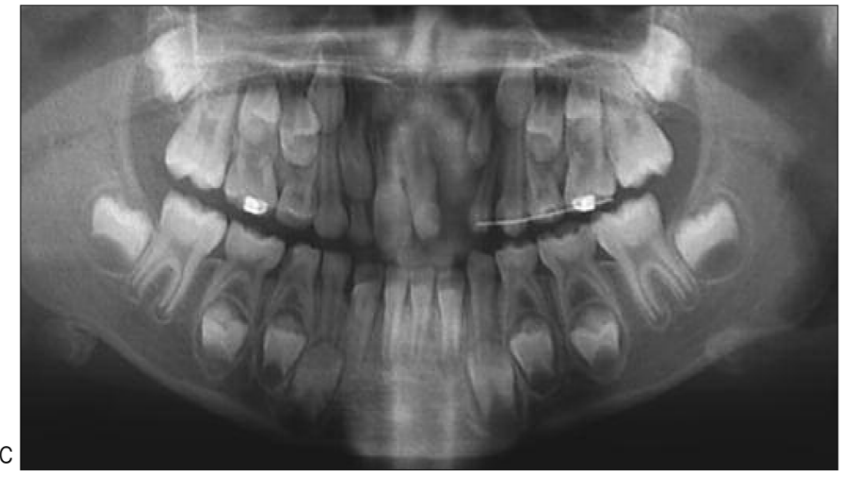

Figures 8 a to $c$

Case 1. Leslie:

a: panoramic $X$-ray film before treatment; b: panoramic film at the end of orthodontic; reparation before graft placement;

c: panoramic film after alveoplasty: the upper left lateral incisor is erupting into the graft.
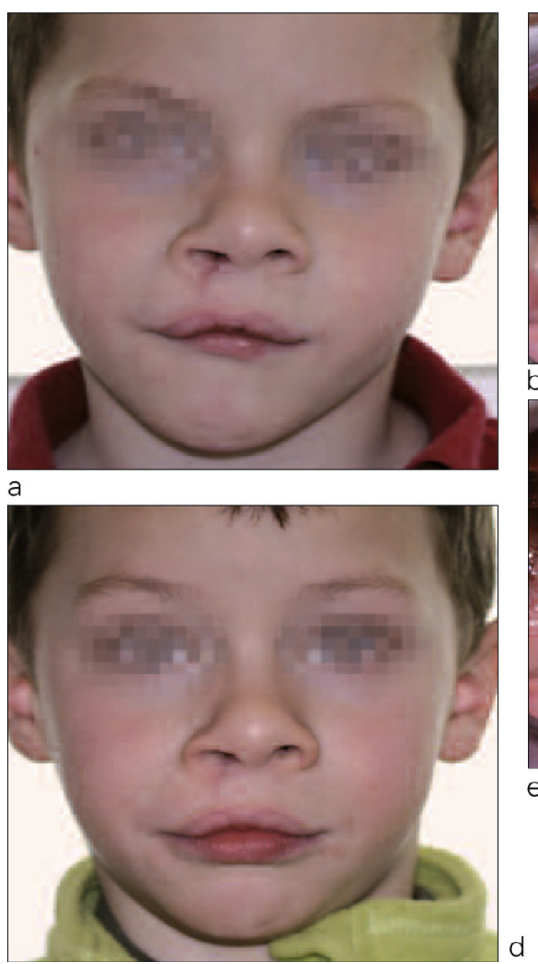

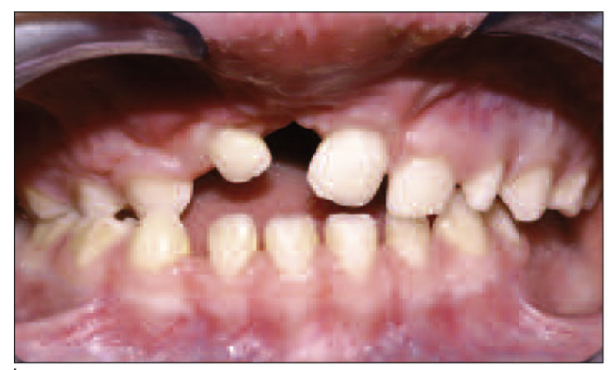

b

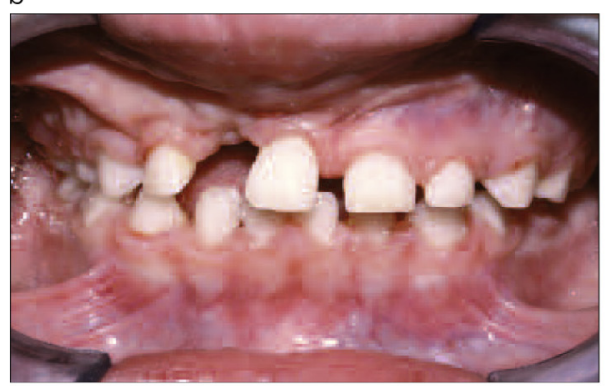

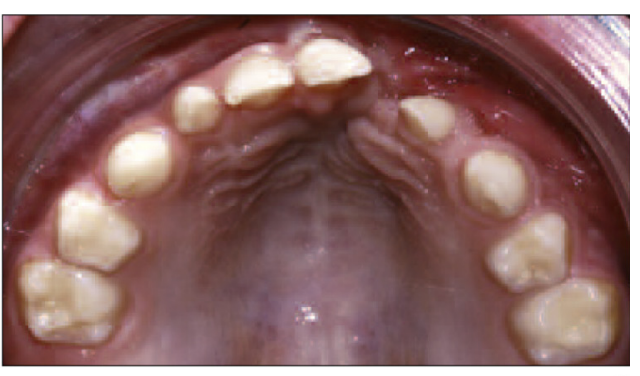

c

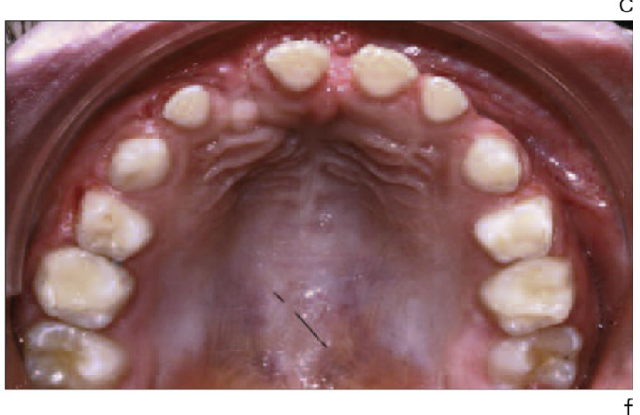

Figures 9 a to $f$

Case 2. Jules:

$a, b, c$ : before orthodontic treatment;

$d, e, f$ : after orthodontic treatment. 

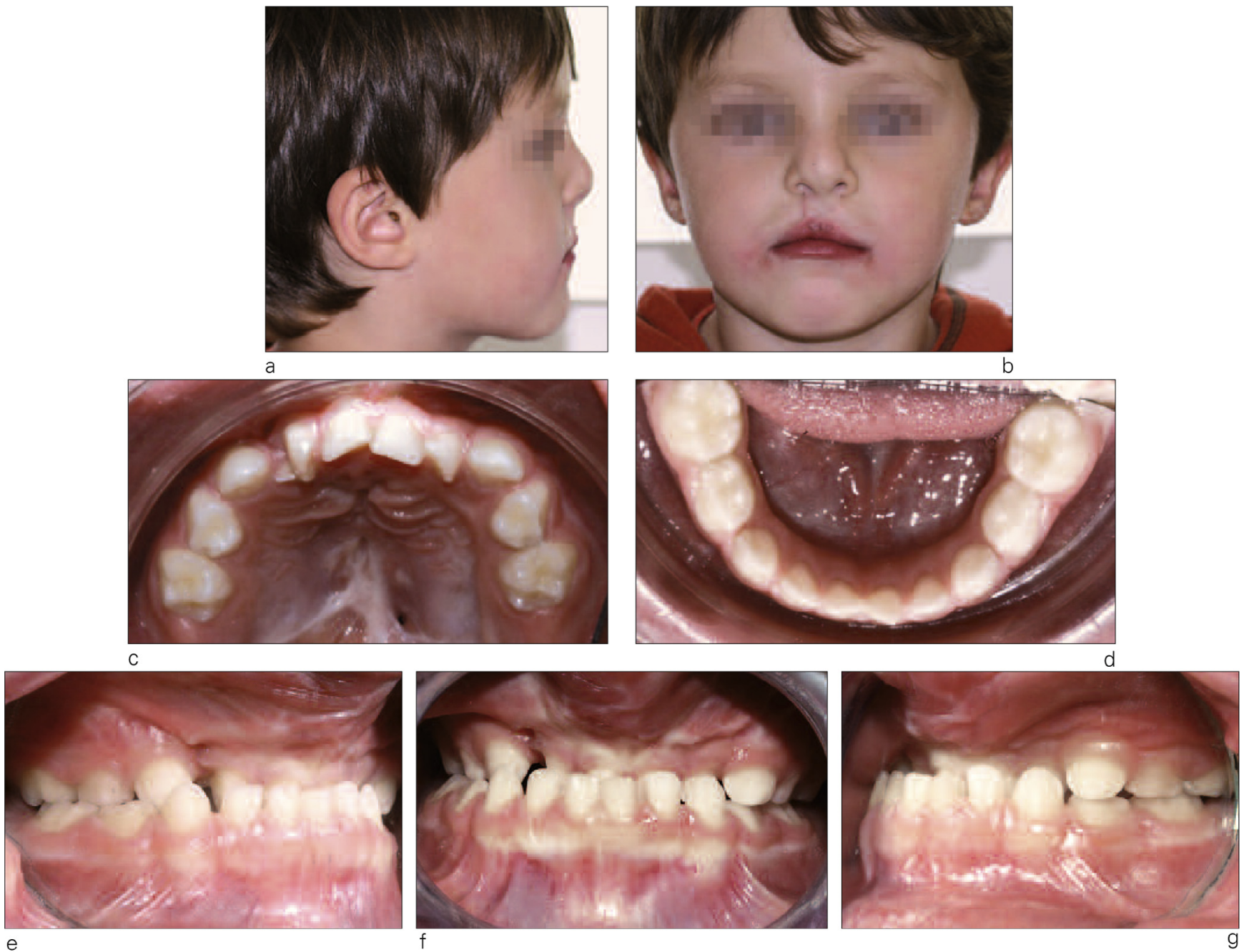

e

f

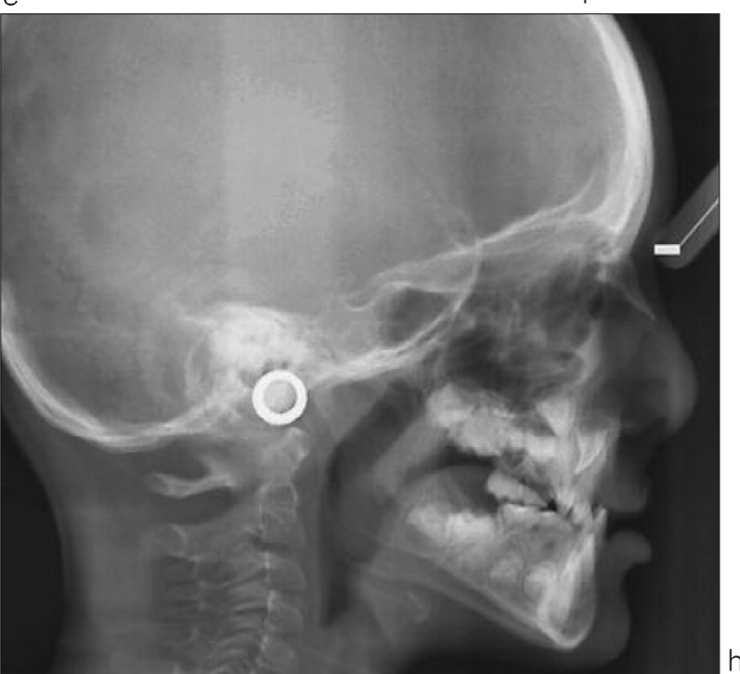

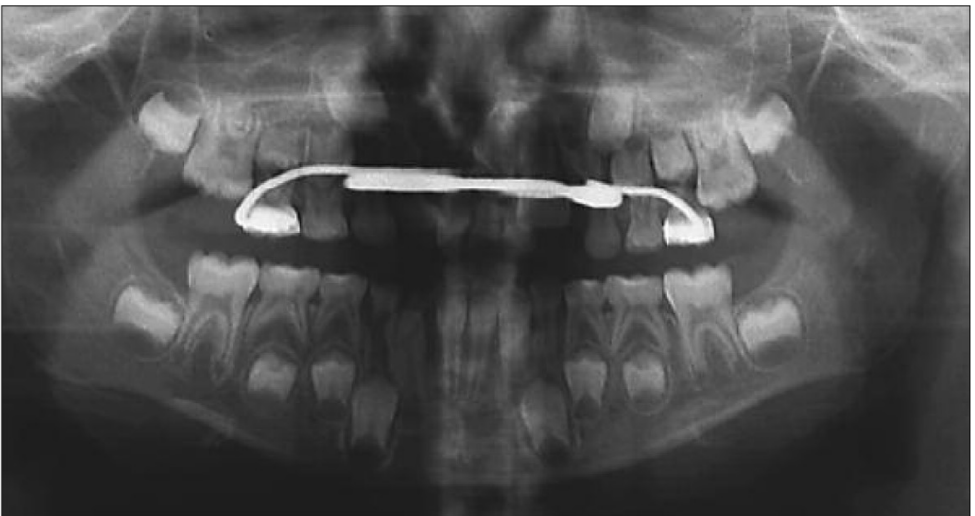

Figures 10 a to $i$

Case 3. Nathan:

before orthodontic treatment. 


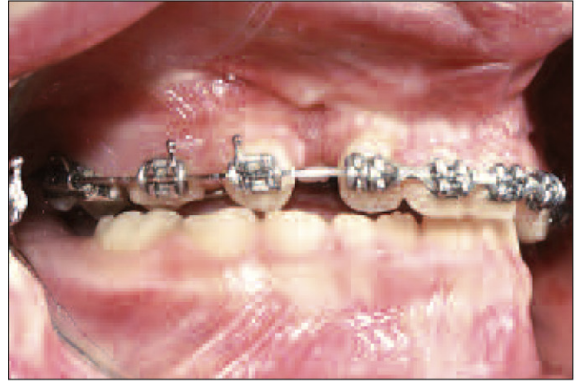

a
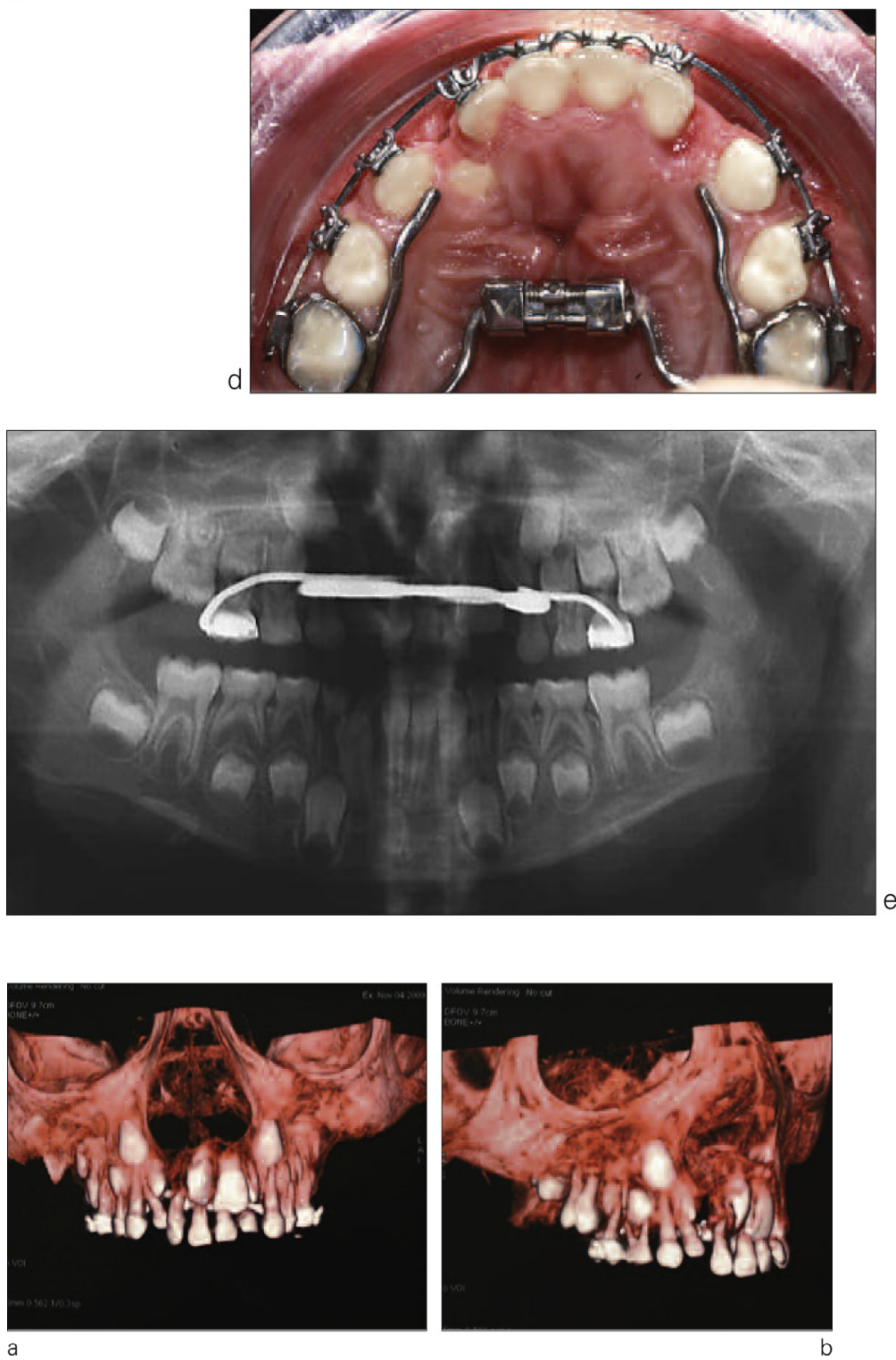

Figure $12 \mathrm{a}$ and $b$

Case 3. Nathan: pre-operative scanner image.

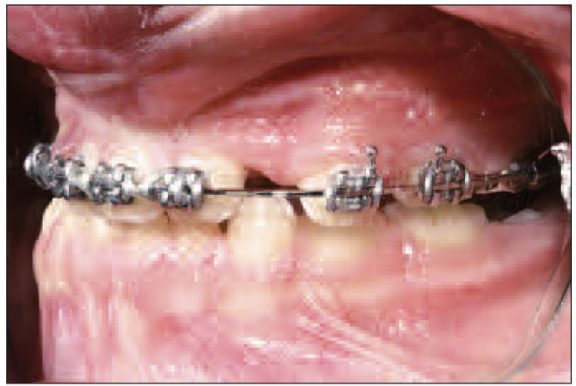

C

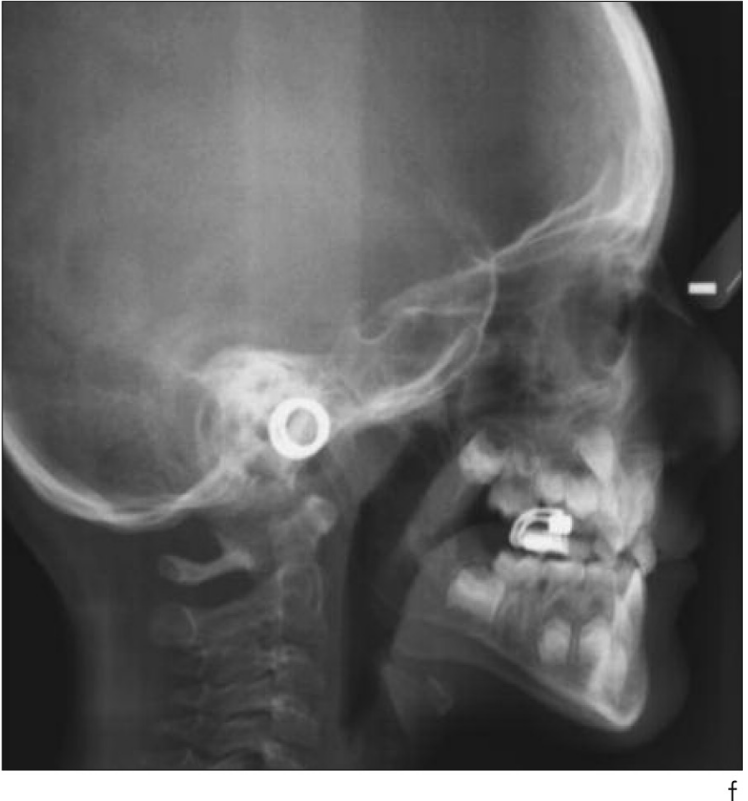

Figures 11 a to $f$

Case 3. Nathan: after orthodontic treatment.

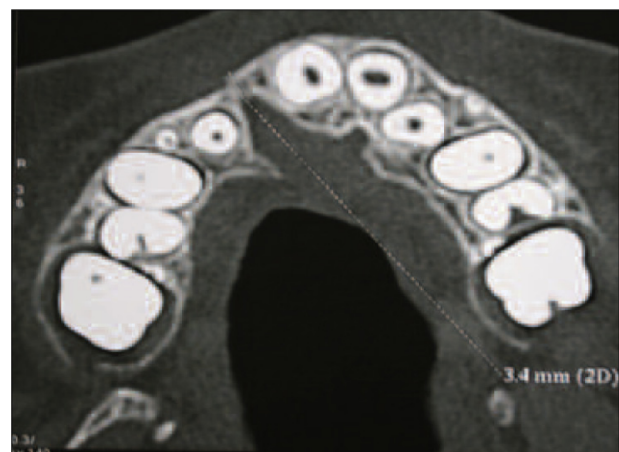

Figure 13

Case 3. Nathan: panoramic occlusal view after alveoplasty: upper right central and incisor teeth have erupted into bone graft. 

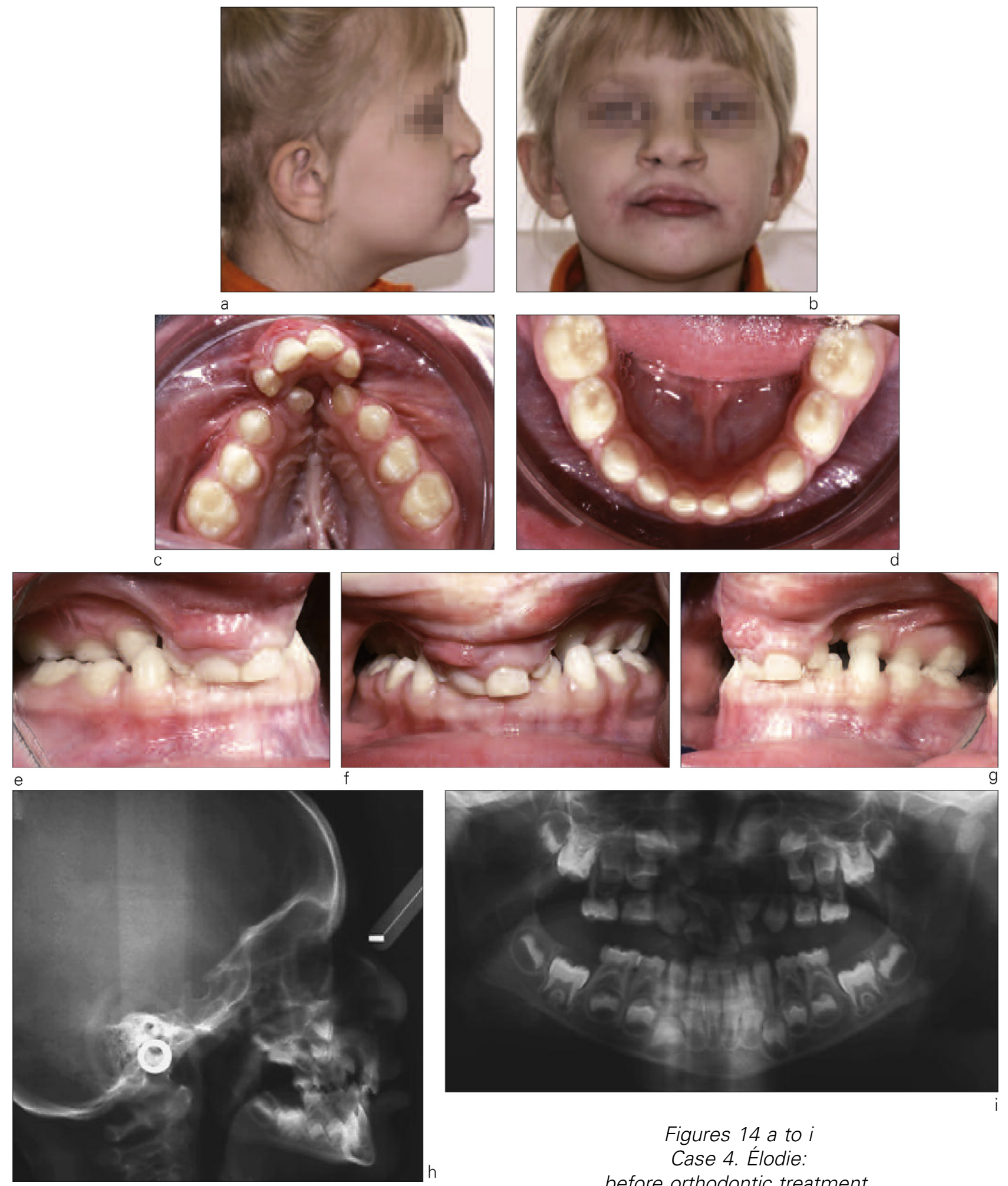

Figures 14 a to $i$

Case 4. Élodie:

before orthodontic treatment. 


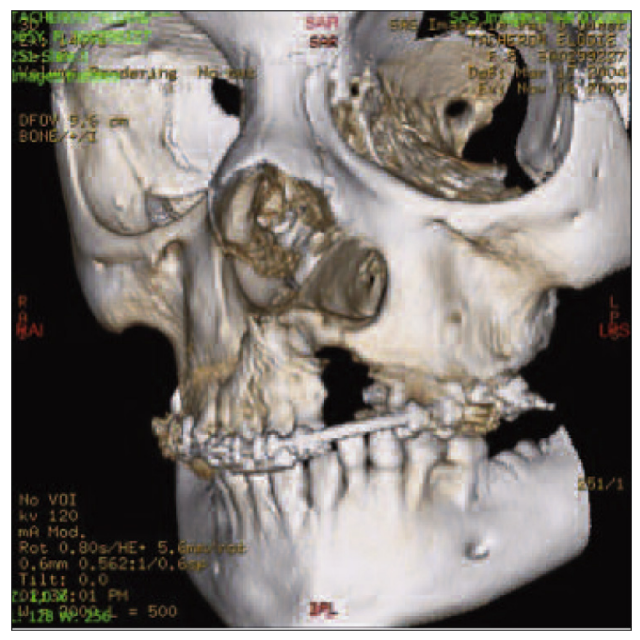

Figure 15

Case 4. Élodie: pre-operative scanner image.
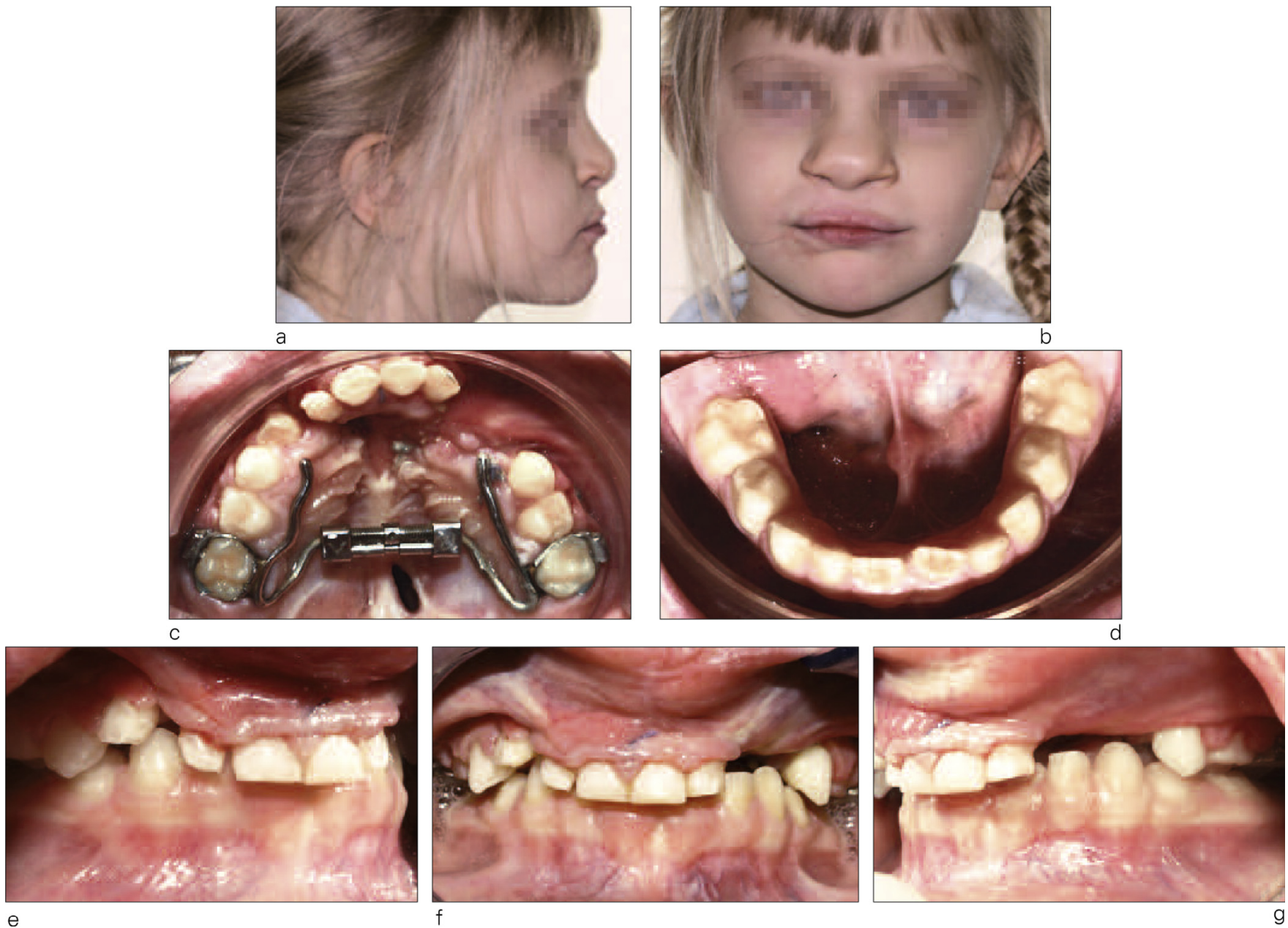

Figures 16 a to $g$

Case 4. Élodie: after orthodontic treatment. 
the appliance to serve as an auxiliary to the surgical procedure by removing brackets but leaving the palatal expansion device in place as a transverse space maintainer. To serve the same

\section{4 - THE EARLY BONE GRAFT}

\section{4 - 1 - Introduction}

The use of an alveolar bone graft was introduced in the early 1950s (Axhausen, 1951) and in 1958 Schrudder and Stellmach proposed the concept of a primary alveoplasty that was based on three objectives:

- to stabilize the premaxilla;

- to stimulate growth through the created osseous bridge;

- and to avoid a later surgical intervention associated with a cheiloplasty.

But a primary alveoplasty has become more and more controversial as many treatment teams abandon it because of poor long-term results and its deleterious effects on facial growth.

So a secondary alveoplasty becomes essential and most treatment teams have incorporated it as an integral component of over-all cleft palate treatment.

The current terminology for alveoplasties that Nylen introduced in 1966 is based on the dental age of patients as well as their physiological age:

- primary alveoplasty: before patients reach the age of one, combined with a cheiloplasty; purpose, when palate expanders are not available, orthodontists may instead use a trans-palatal arch wire, a palatal plate, or a thermoformed splint.

- secondary early alveoplasty before eruption of permanent maxillary canines:

- later secondary alveoplasty, after eruption of the permanent teeth;

- third stage alveoplasty: a reparative graft at the end of the growth period, as preparation for an implant.

\section{4 - 2 - Objectives and benefits}

The objectives and benefits of early secondary alveoplasties, which are now well codified, are both anatomic and physiological. Some are restricted to early alveoplasties; others are shared with later alveoplasties.

- Dental: when the graft is executed before the canines erupt, these teeth may migrate into the site of the cleft where the bone graft will provide periodontal support for adjacent teeth. This will stabilize the results of the early orthodontic treatment.

- Alveolar: alveolar continuity will stabilize the bone fragments, preventing retention of bits of food thus improving oral hygiene. Stabilization of the maxilla will make retention less demanding. The graft 
will add support to the base of the nose and contribute to correct lip positioning, thus improving facial esthetics.

- Palatal: the alveoplasty restores an anatomic barrier between the oral cavity and the nasal sinus passageways. It also helps to treat anterior fistulas and to avoid relapses. In addition it improves phonation by preventing leakage of air through the cleft.

Whether the desired improvement is of facial esthetics, of alimentation, or of respiratory or phonation function, early alveoplasties ameliorate patients' integration into social and academic life.

\section{4 - 3 - Surgical technique}

\section{- Surgical technique}

Surgeons always use autologous spongy cortical bone taken from the iliac crest for grafts placed in secondary early alveoplasties, never heterologous bone or synthetic biomaterial.

Surgeons operate under general anesthesia on patients intubated with a pre-formed catheter placed on the side opposite the cleft and an aleze placed under the patient's hip to afford good protection to the iliac crest. Anesthetists prepare all patients with a maxillary $\vee 2$ nerve block.

Surgeons often carry out a gingivoperiosteoplasty when they place a bone graft to close the alveolar cleft and in the majority of cases re-shape the nostrils and the lips during the procedure.

Before dissecting the cleft, to maintain good antisepsis, surgeons first withdraw the osseous material from the iliac, using a short, offset incision on the crest (fig. 17).

After raising the an osseous cap, the surgeon removes the graft material in an osteotomy then, with aspirated drainage, replaces the cap and

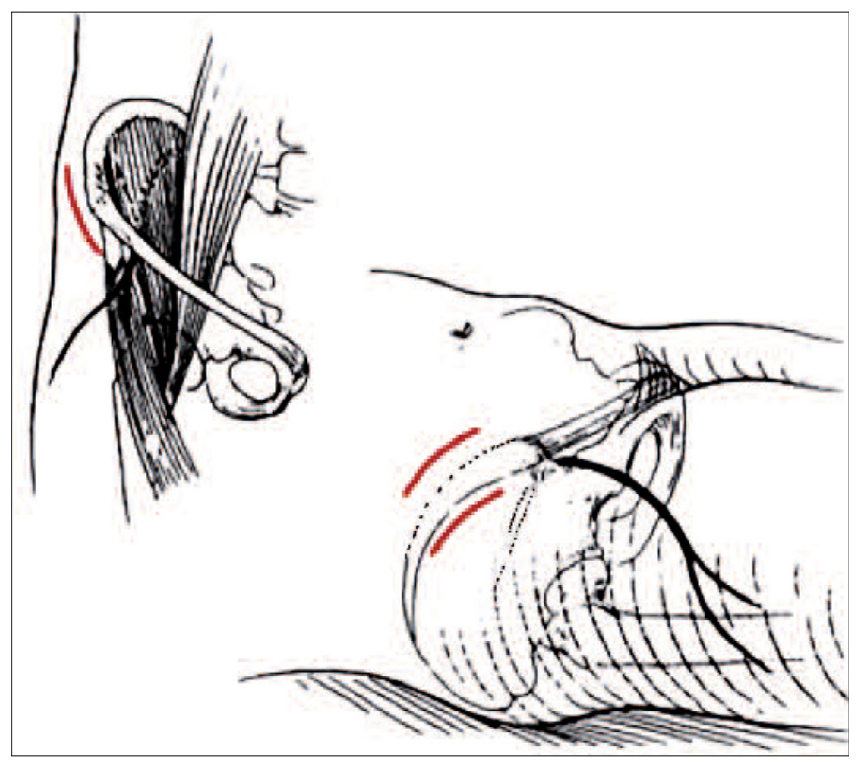

Figure 17

The cutaneous incision, after Converse, Reconstructive Plastic Surgery, Saunders 1977, vol. 1:329. 


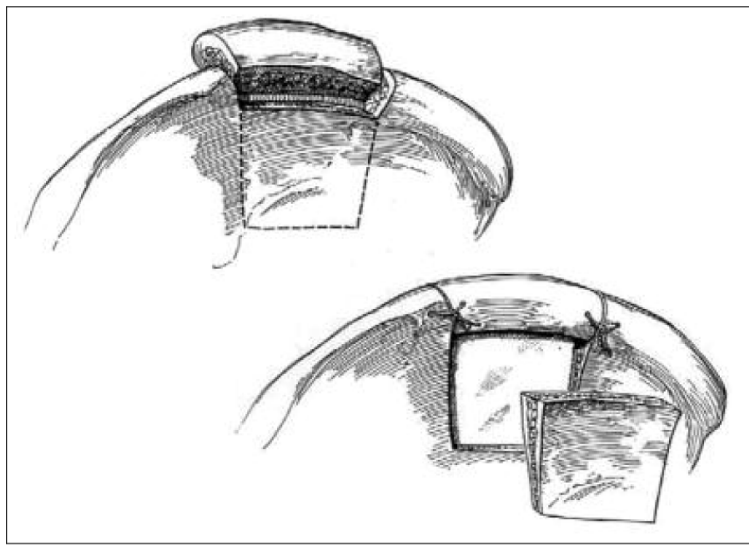

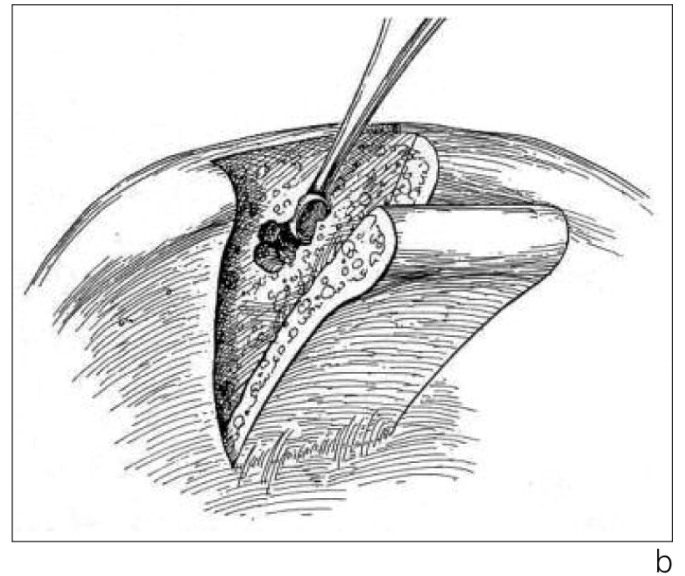

b

Figures $18 a$ and $b$

Raising cortico-spongy bone, after Cohen M. Mastery of Plastic and Reconstructive Surgery. Boston MA: Little Brown \& Company. 1994; vo. 1:105.

stabilizes it by placing slowly resorbable sutures. The graft is thus removed in a cortico-cancellous block that is pulverized in a bone mill (fig. $18 \mathrm{a}$ and $18 \mathrm{~b}$ ).

After making an inverse $T$ incision in the cleft, surgeons uncover tissue starting from the neck of the contralateral central incisor and the side of the small fragment out to the cheek, thus laying back two gingivo-periosteal flaps. With a deep incision into the periosteum, surgeons re-drape and cover the graft, then dissect the cleft

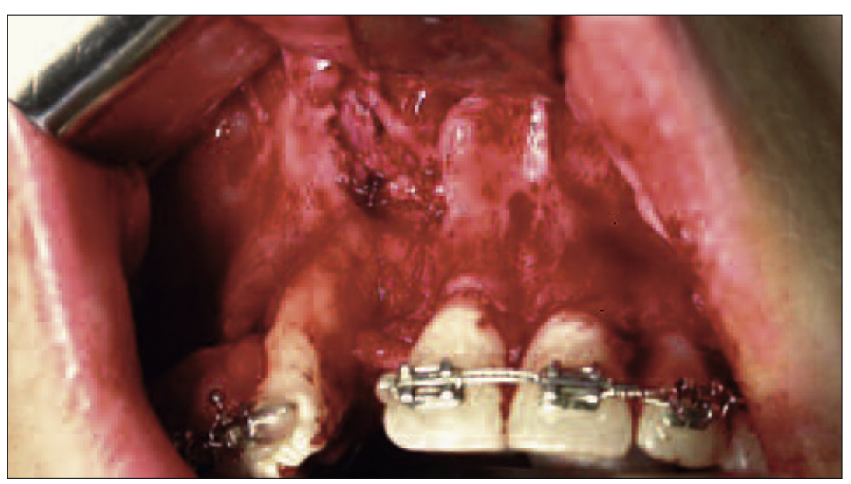

Figure 19 a

Dissection of the cleft. periosteum as far as the piriform orifice freeing the nasal mucosa up to the palate. Surgeons then excise fibrous tissue at the base of the cleft. Our team is zealous in protecting teeth because orthodontic forces will stimulate bone production in the graft. Surgeons then refresh the borders of the cleft with round burs. Then the nasal mucosa and the palatal fibromucosa are tightly sutured, impacting cortico-cancellous block in the cleft (fig. $19 \mathrm{a}$ and b). Surgeons routinely use a graft in apposition to the base of

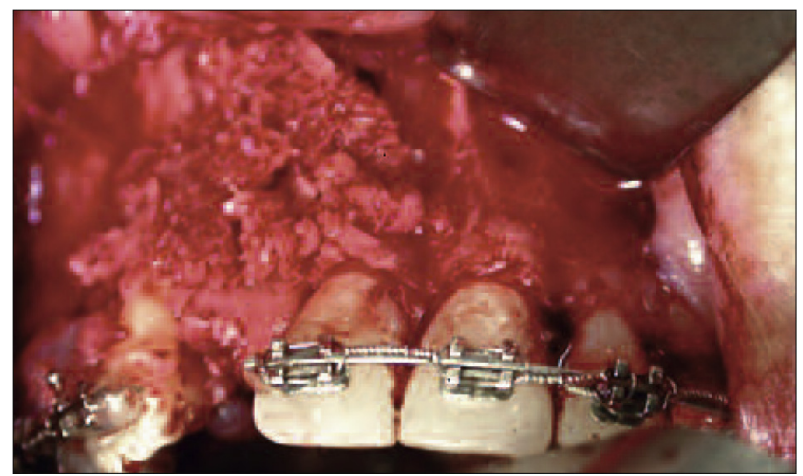

Figure $19 b$

Placement and shaping of the graft. 
the piriform orifice to make the nostrils symmetrical. Knowing that grafts regularly suffer a 20 to $30 \%$ postoperative resorption rate, surgeons also routinely overcorrect cleft repairs.

And, finally, surgeons re-drape the two gingivo-periosteal flaps and use slowly resorbable sutures to close them tightly but without tension (fig. 20).

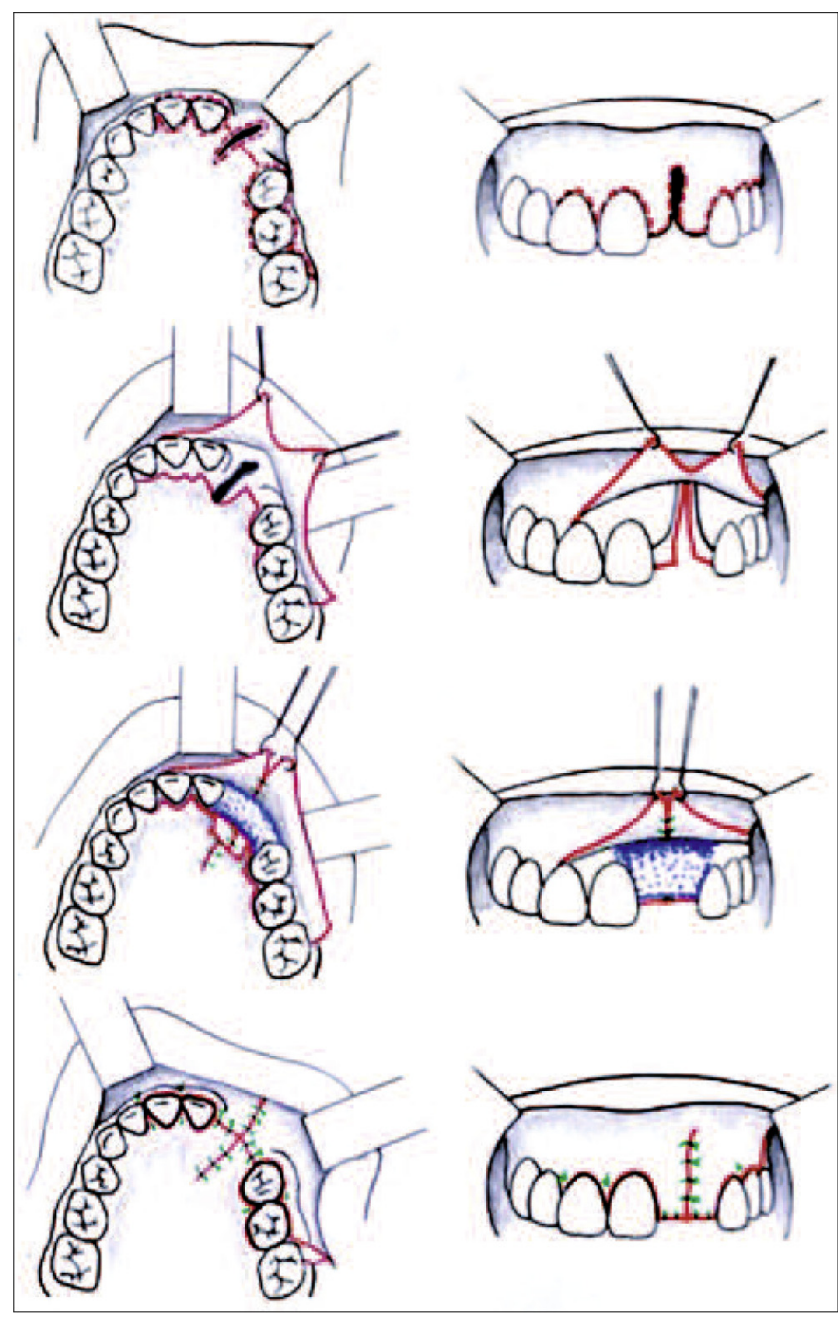

Figure 20

Covering the graft, after Bell W. H. Surgical Correction of Dentofacial Deformities: New Concepts. Philadelphia: W. B. Saunders, 1985.
To perform these procedures surgeons keep patients hospitalized for four days, with patients strictly confined to bed on the first day. On the first day after the operation, patients are allowed to get out of bed briefly with assistance. Healing is checked on the 8th day after the operation, again at 21 days, and then at 45 days.

The multi-disciplinary treatment team re-evaluates patients with a clinical inspection and with panoramic and $3 D$ scanner $X$-rays six months after the operation (fig. 21 a to c).

\section{- The bone graft}

Most authors suggest autogenous spongy bone as the material of choice for grafts because it possesses these essential qualities:

- its rapid re-vascularization that integrates the graft into the maxilla in 3 weeks;

- its excellent resistance to infection;

- its acceptance of re-modeling that allows surgeons to impact it readily;

- and its ready acceptance of teeth migrating into the graft.

\section{- The donor site}

Most authors recommend the iliac crest as the donor site of choice ${ }^{1,3,4,5,9}$, which, of course, requires surgeons to work in two distinct operative regions, but which provides them with sufficient amounts of bone that is rapidly replaced allowing them to harvest more bone six months later. By rigorously adhering to correct technique guidelines surgeons can usually avoid creating dysesthesia in the regions served by the femoro-cutaneous nerve or hematomas. The burden of scar 

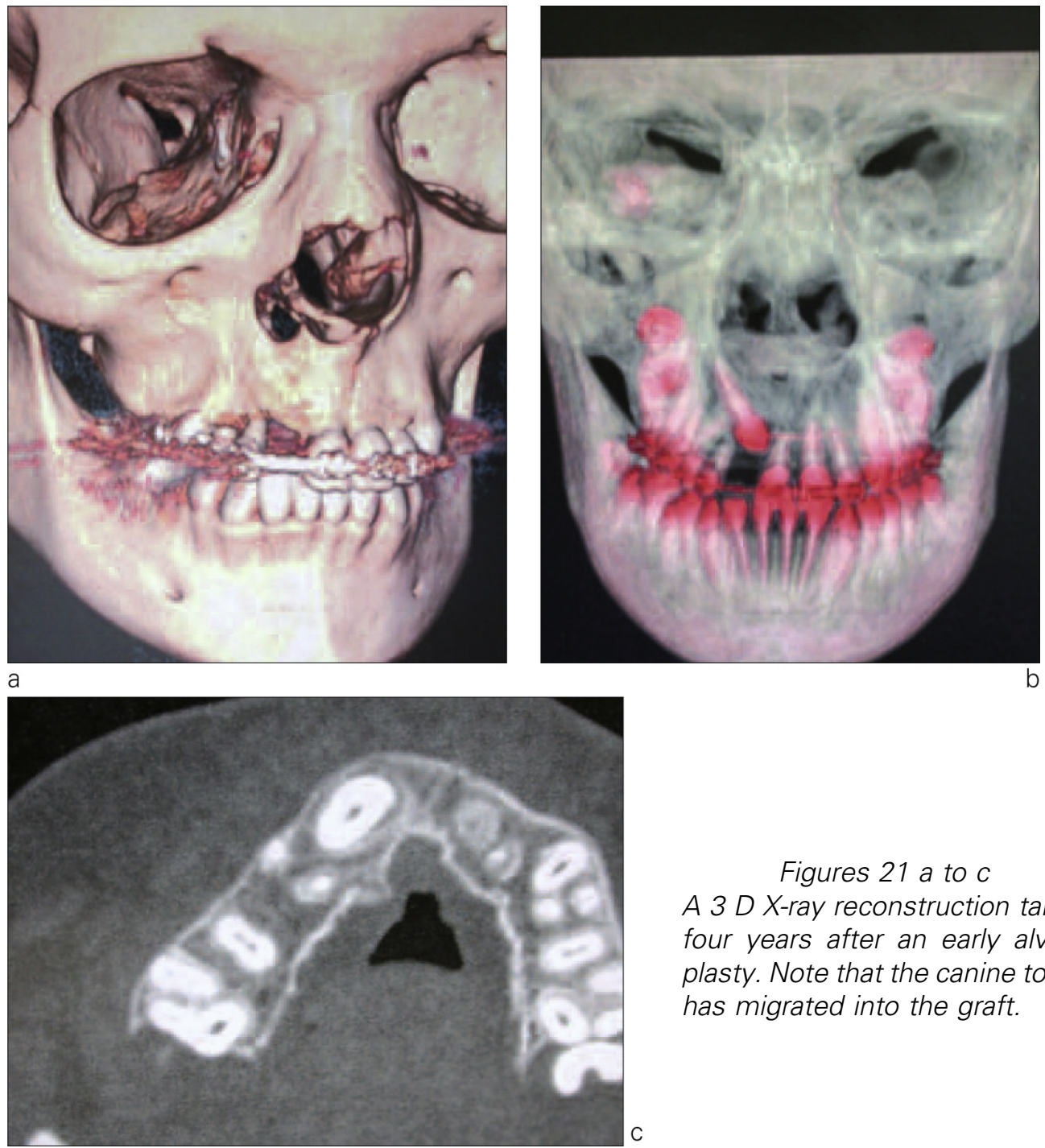

Figures 21 a to $c$

A $3 D X$-ray reconstruction taken four years after an early alveoplasty. Note that the canine tooth has migrated into the graft.

tissue formation can also be kept to a minimum with good surgical technique. By correctly prescribing analgesics and with routine infiltration of longacting local anesthetics at the end of the operation surgeons can keep postoperative pain under good control.

\section{- Closing mucosal flaps}

When surgeons cannot approximate the mucosal borders of the cleft closely enough to place sutures that are not under tension, they routinely insert a sliding gingivo-periosteal flap into the gap. They make the mesial sliding from the small fragment possible by releasing the muco-periosteum with an oblique buccal incision in the molar area. This type of flap, in contrast to a Burian type buccal rotation flap, allows surgeons to add attached gingiva to the graft at the level of the necks of the teeth adjacent to the cleft. 

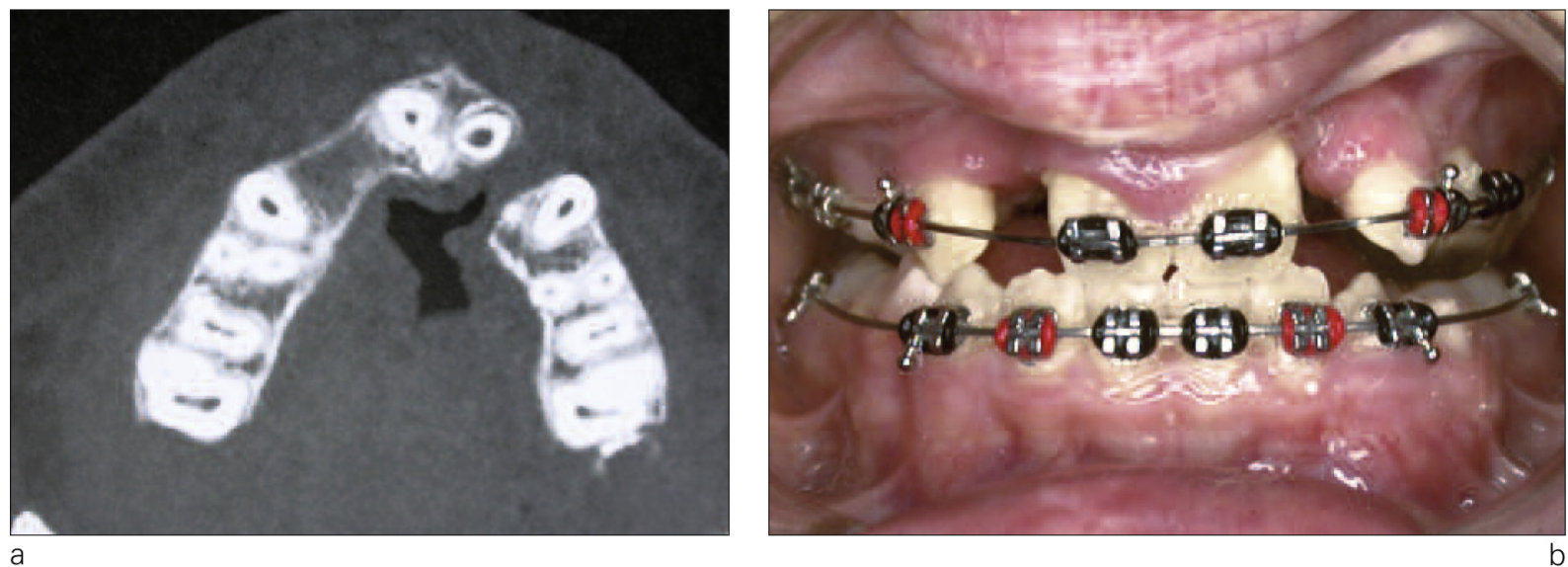

Figures $22 a$ and $b$

$X$-ray and clinical status evaluation at six months of a total bilateral cleft before placement of contralateral graft.

\section{- Special cases}

For patients with bilateral clefts, surgeons make their repairs in two operations 6 months apart. They place the first graft in the site of the larger of the two clefts and then place the

\section{5 - CONCLUSION}

We have been performing early secondary bone grafts on cleft palate patients for more than 5 years. To make an accurate assessment of the benefits of the technique and its associated effects would require a retrospective study evaluating:

- the rate of maxillary growth;

- the number of required associated procedures such as bringing an impacted tooth into the arch, cheek surgery, of later secondary bone grafts;

- the relationship between the assessments and the actual results of late secondary bone grafts. second one a half year later knowing that the iliac donor site will already have completely regenerated the amount of bone previously harvested (fig. 22 a and b)

However, we can look back on our more than five years of experience with early secondary grafts, sum up our impressions of how well objectives were realized, and proffer these comments:

- by aligning the teeth adjacent to the cleft and their alveolar processes through early orthodontic treatment, we have helped our patients maintain good oral hygiene;

- the early stabilization of the maxillary arch preserves the tilting of the smaller fragment;

- closing the palatal cleft restores the barrier between nasal and oral 
cavities thus preventing air leakage and promoting good physiological functioning of nasal breathing and phonation. It also reduces rates of rhino-pharyngeal infection, thus ameliorating hearing:

- the early graft placement reduces the amount of tissue dissection needed and thereby lessens development of restrictive fibrous tissue. It also reduces the amount of bone required for grafts and thereby lessens tissue morbidity at the iliac donor site where bone is harvested;

- it harmonizes the facial esthetics of patients at an early stage thus facilitating their socialization.

All of these perceived benefits encourage us to endorse the type of early alveoplasties we have been performing on our patients for the last five years. They must, of course, be integrated into a multi-disciplinary treatment schedule. The exact timing of the early osseous graft is determined by the anatomical and clinical aspects of the individual's defect and by the course of orthodontic therapy ${ }^{6}$. Many treatment teams follow the plan of correcting the patient's transverse maxillary discrepancy orthopedically and orthodontically before surgical operations are undertaken.

Also like many other treatment teams, we continue orthodontic treatment soon after surgery, especially with the goal of aligning teeth on the borders of the $\mathrm{cleft}^{6}$. This early application of mechano-therapeutic force to the graft stimulates osteogenesis within it and promotes its integration into the body of the maxilla.

It is no longer necessary to demonstrate that the older patients are at operation the higher the rates of failure or partial loss of the graft will be ${ }^{10}$. We have not found a single instance of a break in mucosal continuity in any of the early grafts we have performed during our more than five years of experience with them. To confirm our impressions a retrospective analysis of bone volume at the site of the grafts at the end of our patients' growth periods will be indispensable. To date no significant paper has been published on the long-term evaluation of early secondary grafts for cleft palate patients.

\section{REFERENCES}

1. Abyholm FE, Bergland O, Semb G. Secondary bone grafting of alveolar clefts, $A$ surgical/orthodontic treatment enabling a non-prosthodontic rehabilitation in cleft lip and palate patients. Scand J Plast Reconstr Surg 1981;(5):127-40.

2. Bénateau H, Diner PA, Soubeyrand E, Vazquez MP, Picard A. Les séquelles maxillaires dans les fentes labioalvéolopalatovélaires. Analyse des causes de la rétromaxillie et réflexions sur sa prévention. Rev Stomatol Chir Maxillofac 2007;108(4):297-300. Epub 2007;Aug 8.

3. Bergland O,Semb G, Abyholm FE. Elimination of the residual alveolar cleft by secondary bone grafting and subsequent orthodontic treatment. Cleft Palate J 1986;2(3):175-205.

4. Blanchard-Moreau P, Breton P, Lebescond Y, Beziat JL, Freidel M. Secondary osteoplasy in conge- nital clefts of the primary palate, technic and results of 43 cases. Rev Stomatol Chir Maxillofac 1989; 9(2):84-8. 
5. Boyne PJ, Sands NR. Secondary bone grafting of residual alveolar and palatal clefts. J Oral Surg 1972;3(2):87-92.

6. Captier G, Bigorre M, Mattei L, Delestan C, Montoya P. The secondary bone grafting in cleft lip and palate : technical notes and indications about 62 cases. Ann Chir Plast Esthet 2003;48:20-30.

7. Cohen M, Figueroa AA, Aduss $H$. The role of the gingival mucoperiosteal flap in the repair of the alveo- lar clefts. Plast Reconstr Surg 1989;83 (5):812-9.

8. Durieu du Pradel G, Peyrelongue S, Goyet AS, James I. Evaluation orthophonique de la véloplastie intravelaire précoce chez des enfants porteurs de fentes du palais secondaire ; présentation orale AFEF 2010, Marseille.

9. Hall HD, Posnick JC. Early results of secondary bone grafts in 106 alveolar clefts. J Oral Maxillofac Surg 1983;41(5):289-94.

10. Kortebein MJ, Nelson CL, Sadove AM. Retrospective analysis of 135 secondary alveolar cleft grafts using iliac or clavarial bone. J Oral Maxillofac Surg 1991;49 (5):4938.

11. Krimmel M, Schuck N, Bacher M, Reinert S. Facial surface changes after cleft alveolar bone grafting. J Oral Maxillofac Surg. 2010;69(1):80-3. [Epub ahead of print].

12. Malek René. Cleft lip and palate: lesions, pathophysiology and primary treatment. London: Martin Dunitz, 2001.

13. Mc Comb H, Coghlan BA. Primary repair of the unilateral cleft lip nose: completion of a longitudinal study. Cleft Palate Craniofac J 1996;33:23-30.

14. Mercier J. La gingivoplastie dans les fentes labio-maxillaires. Rev Stomatol Chir Maxillofac 2001;102: 206-10.

15. Prahl-Andersen B, Aartman IH. Satisfaction among parents about treatment-teams of childeren with a cleft lip and/or palate. Ned Tijdschr Tandheelkd 2010;117(4):223-6.

16. Sommerlad BC. A technique for cleft palate repair. Plast Reconstr Surg. 2003;112(6):1542-8.

17. Talmant, JC, Lumineau JP, Rousteau G. Prise en charge des fentes labio-maxillopalatines par l'équipe du docteur Talmant à Nantes : fentes labio-maxillo-palatines. Ann Chir Plast Esthet 2002;47:116-25. 